The health of the people is to a large extent the responsibility of the medical officer and, as nutrition is an important factor in maintaining health, it seems natural that an expert on this subject should be appointed to the staff of the local authority to advise on all matters of feeding. This includes foeding in hospitals, institutions, welfare centres and, to some extent, schools. In many institutions the catering is in the hands of people with little or no knowledge of nutrition, and the cooks are untrained and have often had no experience outside the kitchen in which they are working. It is not surprising, therefore, that the standard of feeding is not always what it should be. If this standard is to be improved, the feeding must be put into the hands of someone who combines a knowledge of nutrition with a practical knowledge of cooking and kitchen management. I cannot stress too strongly that, if dieticians are to hold posts where they are to give advice or be responsible for catering in any form, they must have, in addition to a sound theoretical training, a real knowledge and understanding of cooking, kitchen equipment and management.

There is a very wide field open to dieticians as regards their function in the future, not only in hospitals, schools and industrial canteens, but also in connexion with the new health services, in welfare centres, in prenatal and post-natal clinics and in education.

I have recently seen the report of a nutrition conference held in Canada. The programme of work outlined includes work similar to that which I have mentioned, with this difference, that dieticians in Canada are already well established in the health services. The posts they hold in addition to those which I have mentioned include ones in educational work; this consists of imparting nutritional knowledge directly or assisting in broad programmes of education intended to reach large sections of the public.

Time does not permit me to give in detail the functions involved in these various branches of work, nor is it necessary for me to do so since others will speak of the function of dieticians and the need for them in the different fields of work now open to them.

REFERENCES

King Edward's Hospital Fund for London (1943). Memorandum on Hospital Diet. London: Geo. Barber and Son, Ltd.

Ministry of Health (1945). Circ. Minist. Hlth, no. 44-45.

\title{
The Function of Dieticians and their Role in the Future with Special Reference to the United States and Canada
}

\author{
Mr. A. N. Childs (Empire Tea Bureau, 22 Regent Street, London, S.W.1)
}

In the United States the course of training offered to dieticians places them generally in two categories, those in hospitals and institutions, and those in commerce generally.

\section{The Hospital Dietician}

Although, prior to the war, I had many years of close association with the dieticians in commerce, of which I will speak later, as Catering 
Director to the Canadian Army I was responsible also for the catering in its hospitals in England, France, Holland and Belgium; the present function of a dietician, as now established in the Canadian Army Hospitals, is the result of three years' experience during the war.

It is of paramount importance that the position of a hospital dietician, her responsibility and authority, be clearly defined at the outset from the highest possible level. When this is made clear to all concerned, there will never be any administrative problem or misunderstanding.

In the past, because a dietician received some training as a nurse, it was felt that she should report to the matron. Apart from the fact that the dietician, through some nursing training, has learned to appreciate a nurse's problems in the ward, her work bears no resemblance to that of a nurse. The dietician and catering officer operates mast efficiently as a separate department, reporting to the registrar.

The hospital dietician should be a highly trained specialist. She is responsible for the whole of the catering for all the patients in the hospital, not merely for the preparation of special diets, which usually represent only about 8 per cent. of the total patient strength. The dietician is responsible for all training and, until schools and colleges can give more practical training, the hospital diet kitchen appears to offer the best facilities for training student dieticians and cooks. As the number of special diets issued is small the dietician and catering officer can give the necessary training to students, which could not be successfully under. taken in the main kitchen where the bulk of the food is prepared.

The dietician and catering officer should, apart from having a comprehensive knowledge of nutrition, have a practical knowledge of the preparation and distribution of food in bulk, be able to allot all personnel under hor jurisdiction to obtain the greatest efficiency and the best working conditions possible, be able to requisition for all food commodities, to plan special diets and all menus, not only from a nutritional point of view but also in relation to the equipment in her kitchens and in relation to costs. She should be thoroughly familiar with the operation of all kitchen equipment and be able to instruct others in its efficient use, have a good knowledge of kitchen planning and arrangement, and generally be a good kitchen manager.

It is most important that she should work closely with the physician and surgeon, and be able to advise on the subject as well as interpret their wishes regarding the dietary care of their patients.

The hospital dietician should visit patients receiving special diets as frequently as possible to ascertain that the food prepared is, in fact, being consumed and duly contributing to their recovery.

Through the matron she should arrange to give lectures, particularly to new nurses, and instruction in the feeding of patients, and it should be made perfectly clear to the nurses that they are responsible to the dietician for the proper serving of food to the patients when it arrives in the wards.

\section{The Dietician in Commerce}

The function and role of a qualified dietician who falls within this particular category can best be described from my personal experience from 1927 to the beginning of the war just ended.

voL. 4,1946 ] 
In 1927 my Company, a nationally known chain restaurant organization in the United States, decided to employ dieticians for the purpose of assisting the managers of the various restaurants to improve the standard of catering, and to introduce into its menus the idea of nutritive value. At that time menus were entirely à $l a$ carte; new dishes began to appear emphasizing the values of fruit, vegetables, and dairy produce, and the menus showed in the margin the number of Calories in each dish offered, and those items rich in vitamins. This change in menu policy and the presence of dieticians in this chain of restaurants created quite a sensation.

Many dieticians were thus employed; they came from all over the United States, some straight from college, others with hospital experience, and a few with a little commercial experience, but it was obvious that the training in the different colleges varied considerably. It was soon realized by the Company that these ladies were not of much assistance to the managers since they had had very little practical training that was of value outside a hospital or institution.

Training facilities to fit them for their new role in commerce were then set up. They were given experience in practical cookery at the experimental kitchen where they were taught to experiment on the production of new dishes, and to improve on the old. They spent some time with the buyers of such commodities as fruit and vegetables, meat and fish, dairy produce and groceries, to make them thoroughly familiar with the standard of merchandise that was being purchased, so that they would recognize the grades suitable to the various restaurants.

They were trained in the menu department to plan menus in accordance with the foodstuffs available, this information being transmitted to them. from the purchasing department. In the menu costing department they were taught how to calculate the cost per portion of every recipe submitted by the experimental kitchen. In the clerical department of a restaurant they became familiar with the handling of invoices, stocktaking, taking inventories, and merchandise control. They worked in every food preparation department within a restaurant. Here they gained practical experience of food preparation which enabled them to detect errors in food preparation, and to show others how to correct them, and thus gain the confidence of all the staff. Finally, from a period of contact with the manager of a restaurant, they gained experience in the handling of kitchen staff, in arrangement of work and in other branches of kitchen management.

After the successful completion of this training a dietician was able to assume the position of catering controller and dietetic adviser in a restaurant. The total period of the training varied from a few months to a year, depending upon the student, and represented incidentally a great expense to the Company.

During the first twelve months of the new regime the public did not take very kindly to this new fad, as they called it, in food service, and resented the idea of adding up the number of Calories to satisfy themselves that they were well fed. It was, therefore, decided to relieve customers of the trouble of balancing their own meals from the à la carte menu then in use, and to offer well balanced meals, ready planned at varying prices. Here was the beginning, on a large scale, of table d'hote meals in the popular priced restaurants in the United States. 
As might be imagined, this experiment of employing dieticians and offering meals of recognized nutritive value was being closely watched by other owners of restaurants, but the fact that dieticians had to be trained did not appeal to the prospective employers; the dieticians, however, through their Association, united, and today the student dietician in colleges in the United States is given substantially the same training for this purpose as we ourselves gave in 1927. Today, qualified dieticians in the United States are very much sought after, since it is now appreciated that they are well trained, and can take their place and assume responsibility quickly.

\section{Discussion}

Miss M. Andross (College of Domestic Science, Park Drive, Glasgow), opener: The British Dietetic Association has done a grand job. In 10 years they have instituted a new profession for women and, what is much more difficult, they have induced the conservative British public to accept it.

Like Miss Pybus, I should like to see a standard training for all, but unfortunately, the new dietician, according to Mr. Childs, is expected. to fill so many different posts that this would be difficult to arrange. If we insist on a B.Sc., no university, at least in Scotland, would consider a course which did not include natural philosophy or mathematics in the first year. This is far removed from catering for 3000 children. We should lose many excellent dieticians by insisting on their passing this examination. A university entrance qualification we must have but no further purely educational course should be insisted upon except in nutrition, chemistry, biochemistry, physiology and bacteriology. The dietician is now expected on the one hand to work in a metabolism ward or a food research laboratory, do food surveys and teach other dieticians; in such spheres she must have a B.Sc.; her work would not be recognized unless she had. On the other hand, she is expected to be a hospital caterer, a supervisor of school meals, or a hospital dietician. In all those posts, as Miss Broatch has pointed out, she must be able to cook on a large scale. She must also, as Mr. Childs has said, understand the management of staff, and the buying and general economics of large scale budgeting. For such an individual an ordinary B.Sc. is poor training. She would need a further training for two years, according to the experts. Mr. Childs has put it at one year but $\mathrm{I}$ presume he means beginning with a trained dietician. Five years' training, not counting the necessary experience, would be too long to demand for the salaries paid in most cases. Therefore $I$ would suggest that a B.Sc. course should be established for those students with definite scientific leanings, but that there should be an alternative diploma for the other type of student. This would include a knowledge of chemistry and very full training in all forms of cookery, buying, budgeting, management of staffs and presentation of food. Dietetic cookery should also be in. cluded; apart from the instruction about diet in disease, it gives the best training in accuracy in the use of food tables and the preparation of

menus. An engineering and electrical course would have to be included also so that students would have the knowledge necessary to make full voc. 4,1946$]$ 